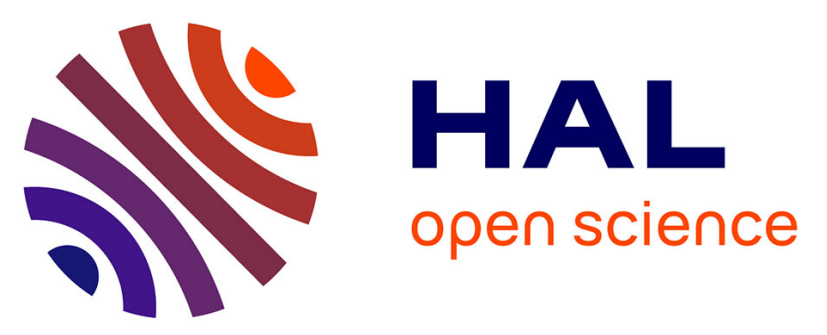

\title{
MEASUREMENTS OF THE OPTICAL REFLECTIVITY AND MICROWAVE DIELECTRIC CONSTANT OF Na-NH3 SOLUTIONS IN THE METAL-NONMETAL TRANSITION RANGE
}

\author{
M. Schlauf, G. Schönherr, R. Winter
}

\section{To cite this version:}

M. Schlauf, G. Schönherr, R. Winter. MEASUREMENTS OF THE OPTICAL REFLECTIVITY AND MICROWAVE DIELECTRIC CONSTANT OF Na-NH3 SOLUTIONS IN THE METALNONMETAL TRANSITION RANGE. Journal de Physique IV Proceedings, 1991, 01 (C5), pp.C5185-C5-190. 10.1051/jp4:1991522 . jpa-00250646

\section{HAL Id: jpa-00250646 https://hal.science/jpa-00250646}

Submitted on 1 Jan 1991

HAL is a multi-disciplinary open access archive for the deposit and dissemination of scientific research documents, whether they are published or not. The documents may come from teaching and research institutions in France or abroad, or from public or private research centers.
L'archive ouverte pluridisciplinaire HAL, est destinée au dépôt et à la diffusion de documents scientifiques de niveau recherche, publiés ou non, émanant des établissements d'enseignement et de recherche français ou étrangers, des laboratoires publics ou privés. 
MEASUREMENTS OF THE OPTICAL REFLECTIVITY AND MICROWAVE DIELECTRIC CONSTANT OF Na-NH ${ }_{3}$ SOLUTIONS IN THE METAL-NONMETAL TRANSITION RANGE

\author{
M. SCHLAUF, G. SCHÖNHERR and R. WINTER \\ Institute of Physical Chemistry and Materials Science Center, Hans-Meenwein-Strasse, D-3550 Mar- \\ burg/Lahn, Germany
}

\begin{abstract}
We present measurements of the optical reflectivity and microwave dielectric constant of $\mathrm{Na}-\mathrm{NH}_{3}$ solutions in the concentration range around 4 mol-\% metal, i.e. at conditions where the transition from localized to itinerant electronic states takes place. The concentration- and temperature dependence of the optical constants approaching the metal-nonmetal transition is discussed.
\end{abstract}

\title{
1. Introduction
}

By dissociation of dissolved sodium in liquid ammonia, solvated electrons are formed in different states, depending on concentration and temperature $/ 1 /$. In very dilute solutions (< $10^{-3}$ mol-\% $\mathrm{Na}\left(\mathrm{MPNa}=100 \cdot \mathrm{x}_{\mathrm{Na}}\right)$ ), the electrons are localized. Their optical properties have been extensively studied $/ 2 /$. They exhibit a broad intensive asymmetric absorption band with the maximum around $0.8 \mathrm{eV}$. With increasing sodium concentration (> $10^{-3} \mathrm{MPNa}$ ), diamagnetic species are formed, generally, a spin pairing equilibrium $2 \mathrm{e}^{-}=\mathrm{e}_{2}=$ is postulated. An increase in temperature favours the unpaired state $/ 1 /$. The absorption spectrum of the diamagnetic species shows a small red shift of about $0.05 \mathrm{eV}$ relative to that of the paramagnetic electrons $/ 2,3 /$. At still higher sodium concentrations ( $>2 \mathrm{MPNa}$ ), the dark blue colour of the dilute solutions is replaced by a bronze reflectivity, characteristic for the onset of the metallic state. Characteristic changes in a variety of physical properties indicate that in $\mathrm{Na}-\mathrm{NH}_{3}$ solutions the transition from localized to itinerant electronic states occurs in the vicinity of the consolute point of the miscibility gap $\left(\mathrm{T}_{\mathrm{c}}=231.5 \mathrm{~K}, \mathrm{x}_{\mathrm{Na}}=0.0415(4.15\right.$ MPNa)).

We have measured the optical reflectivity in the photon energy range from $0.6 \mathrm{eV}$ to $5 \mathrm{eV}$ of $\mathrm{Na}-\mathrm{NH}_{3}$ solutions in the concentration range from $1 \mathrm{MPNa}$ to $12 \mathrm{MPNa}$ at temperatures ranging from $233 \mathrm{~K}$ to $273 \mathrm{~K}$. The reflectivity was measured for the incident light nearly normal to the fluid sample behind a quartz window. In order to extract the optical constants $\epsilon_{1}(\hbar \omega)$ and $\sigma(\hbar \omega)$, a simple Drude-Lorentz model has been applied. For experimental details and the data analysis see /4-6/. For the measurements of the low frequency dielectric constant, a time domain reflectivity method (TDS) has been applied /7/. A frequency of 0.5 
GHz has been chosen. The experimental data yielded after normalization and Fourier transformation the real and imaginary part of the complex dielectric constant.

\section{Results and Discussion}

Figure 1 shows the optical reflectivity at the quartz-solution interface as a function of photon energy for some selected concentrations at $\mathrm{T}=233 \mathrm{~K}$. The form of the reflectivity curves for concentrations > 5.6 MPNa exhibits the typical behaviour of metals in the region of their plasma edge. The spectra of the lower concentrations show an additional contribution from localized states, i.e. both free and bound electron states seem to contribute to the spectral shape. Due to the limited photon energy range, no Kramers-Kronig inversion could be performed to extract the optical constants from the reflectivity data. Instead, a simple DrudeLorentz model has been applied, consisting of a simple analytical form for the dielectric functions, which contain a contribution from damped oscillators for the bound electrons and a Drude part for the quasi-free electrons /4-6/. Besides the free electron contribution, only one damped oscillator was necessary to describe the experimental reflectivity curves satisfactorily. Figure 2 shows the optical constants for all concentrations at $T=233 \mathrm{~K}$ (the $\sigma(\hbar \omega)$-data were extrapolated to lower energies than that measured $(0.6 \mathrm{eV}))$. The Drude-like behaviour of $\epsilon_{1}(\hbar \omega)$ and $\sigma(\hbar \omega)$ is obvious for concentrations > 7.5 MPNa, whereas for concentrations < 5.6

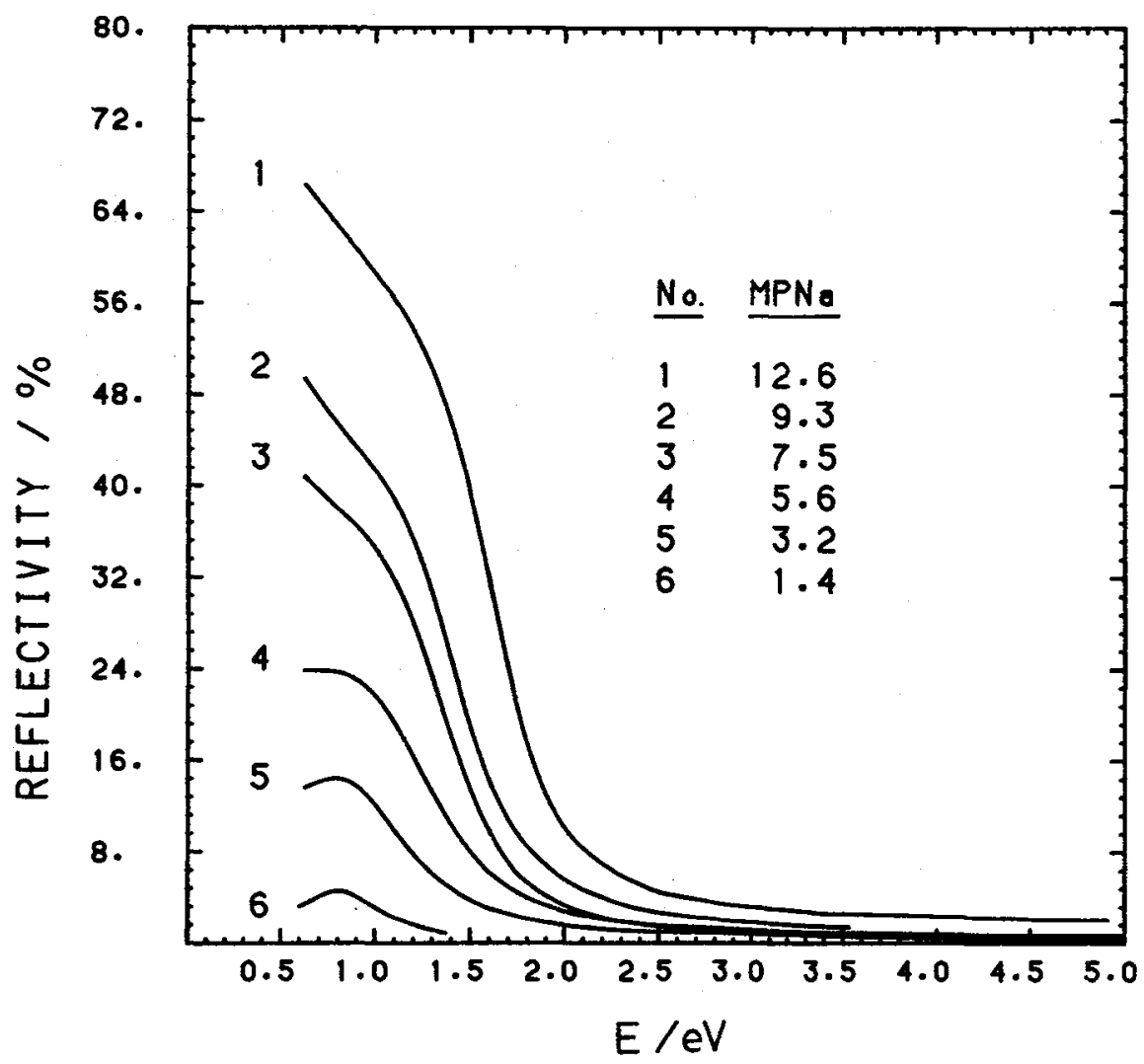

Fig. 1 Optical reflectivity $\mathrm{R}(\hbar \omega)$ at the quartz/Na-NH 3 solution interface for several sodium concentrations $(T=233 \mathrm{~K})$. 
MPNa an additional contribution from localized species appears, which rapidly increases with decreasing metal concentration. A detailed analysis of the data reveals that the amount of bound states is continuously decreasing, but still present at the highest concentrations measured. At 12.6 MPNa, a contribution of still $8 \%$ bound states has been obtained from the model applied. The reflectivity data of the low concentrations ( $<3.2 \mathrm{MPNa}$ ) could be fitted best with one simple electron oscillator only, without any contribution from quasi-free electrons. The position, temperature dependence and half width of the absorption band for the 1.4 MPNa solution resemble those values known for the diamagnetic solvated electron species $/ 2,3 /$.

As can be seen from Figure 3, for e.g. the 5.1 MPNa solution, the temperature dependence of the optical constants in the concentration range where the metal-nonmetal transition (MNMT) occurs, is rather strong. With rising temperature, the optical band, which is characteristic for the localized electronic state, vanishes more and more, thus showing that the solution becomes more metal-like with increasing temperature. The contribution from itinerant electrons increases about $10 \%$ upon increasing the temperature from 233 to $269 \mathrm{~K}$. This clearly demonstrates that the locus of the MNMT shifts towards lower concentrations with increasing temperature.

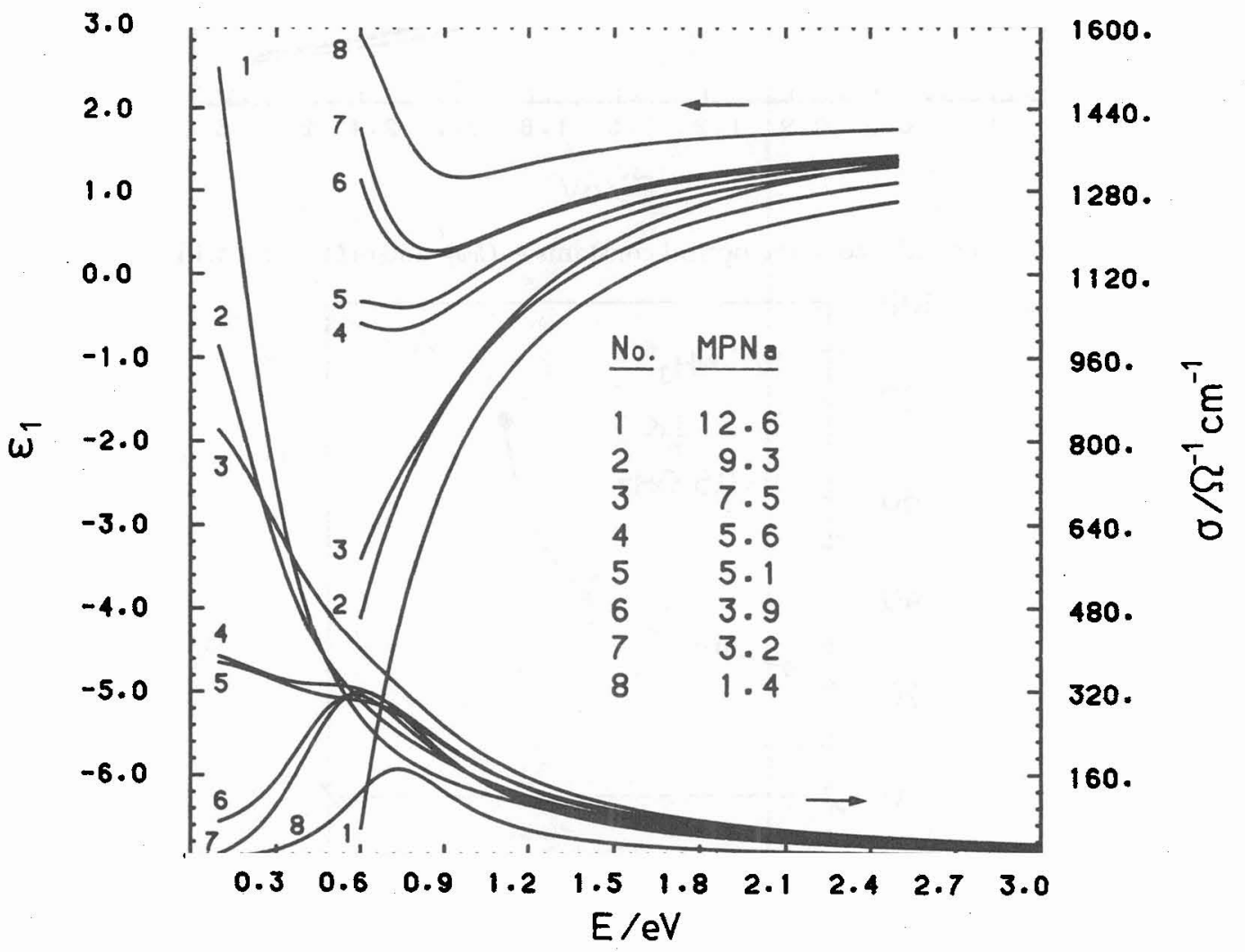

Fig. 2 Concentration dependence of the optical constants $\epsilon_{1}(\hbar \omega)$ and $\sigma(\hbar \omega)$ of $\mathrm{Na}-\mathrm{NH}_{3}$ solutions at $\mathrm{T}=233 \mathrm{~K}$. 


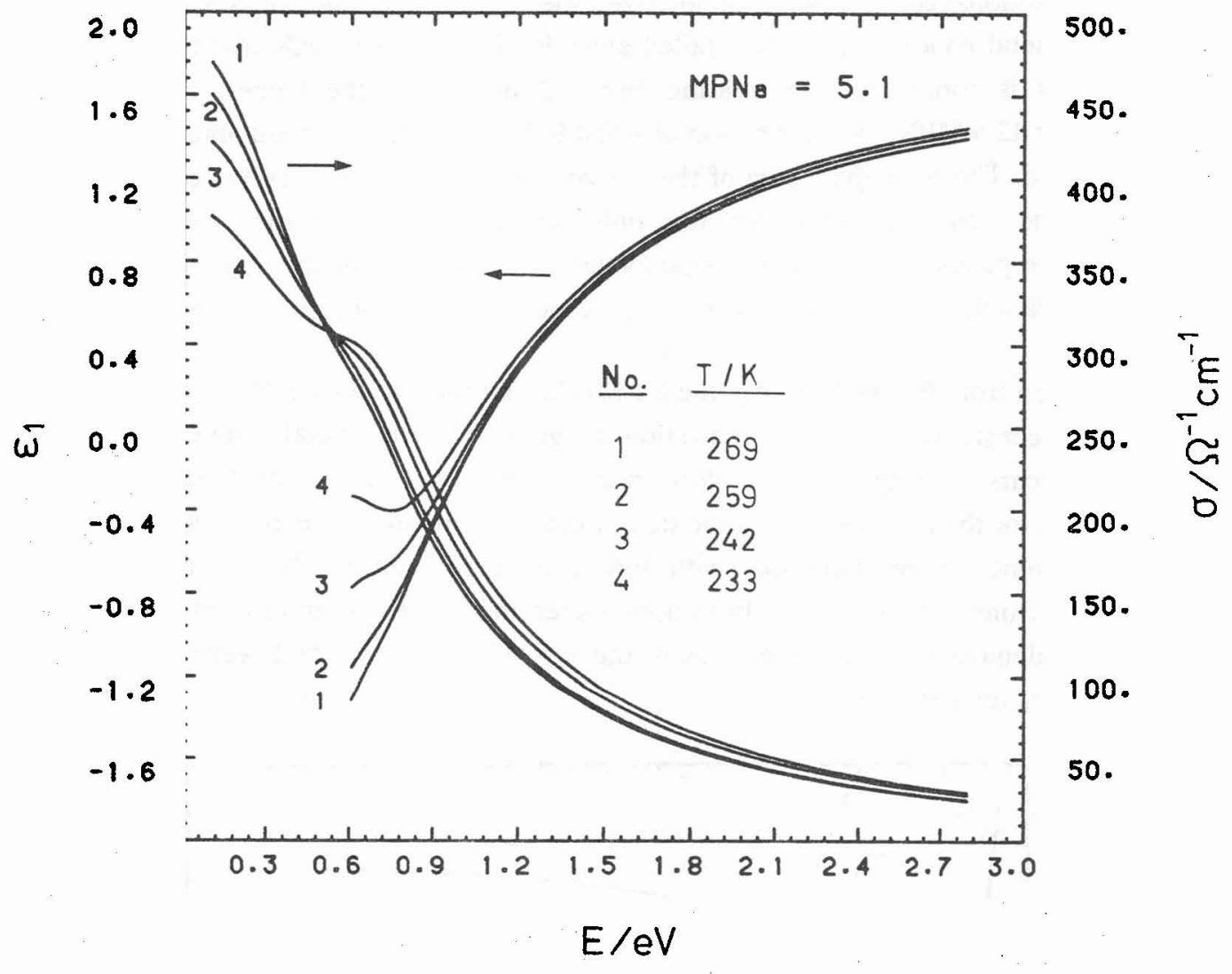

Fig. 3 Temperature dependence of the optical constants $\epsilon_{1}(\hbar \omega)$ and $\sigma(\hbar \omega)$ for a 5.1 MPNa solution.

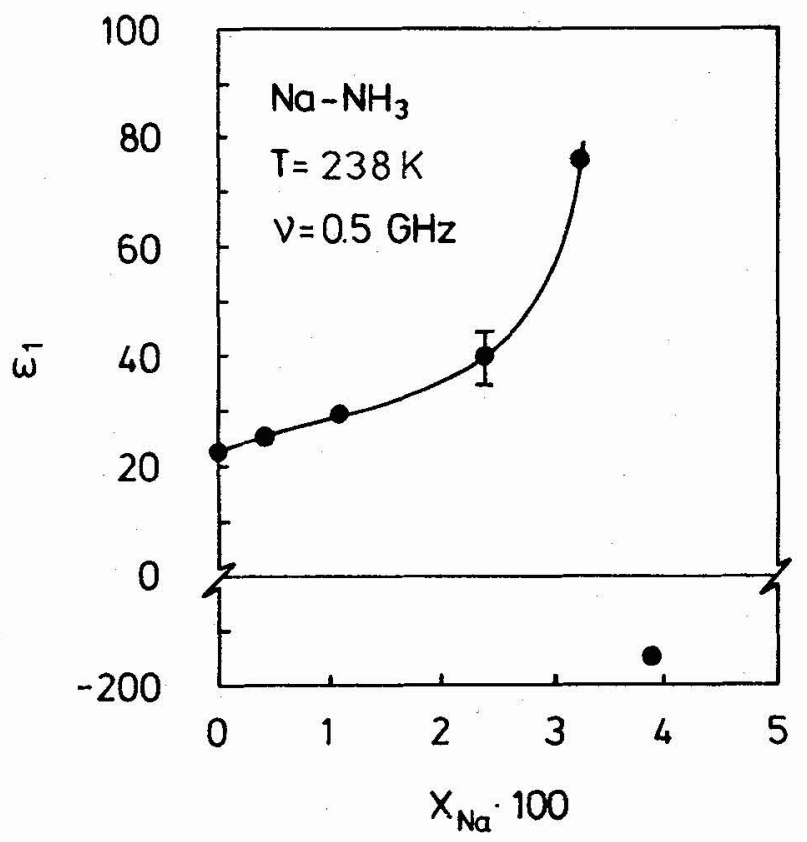

Fig. 4 The concentration dependence of $\epsilon_{1}$ at $0.5 \mathrm{GHz}$ for $\mathrm{Na}-\mathrm{NH}_{3}$ solutions at $\mathrm{T}=238 \mathrm{~K}$. 
In recent years, attention has especially been focused on the behaviour of the real part of the dielectric constant, $\epsilon_{1}$, approaching the MNMT from the nonmetallic side. From the simple Herzfeld criterion $/ 8,9$, which is based on the Clausius-Mossotti equation, as well as from the the more recent scaling theories $/ 9-11 /, \epsilon_{1}(\hbar \omega \rightarrow 0)$ is expected to diverge at the MNMT for T $\rightarrow 0 \mathrm{~K}$. Millikelvin experiments on doped semiconductors $/ 11 /$ have found this expected divergence of $\epsilon_{1}$. No complete theory for the corresponding behaviour of $\epsilon_{1}$ for "hot" systems like metal-ammonia solutions is available so far, however. Figure 4 exhibits the experimental

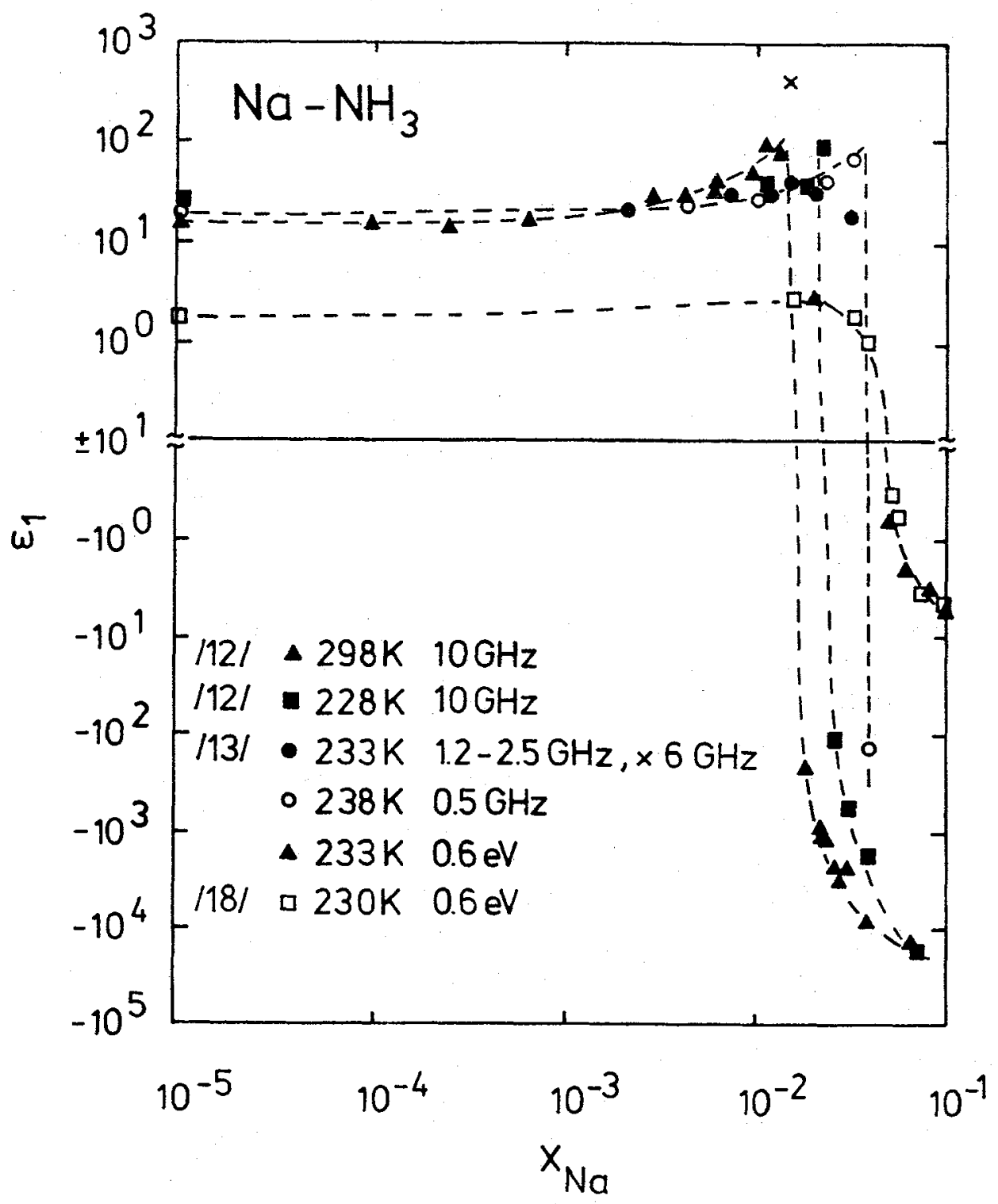

Fig. 5 The optical and microwave dielectric constant $\epsilon_{1}$ as a function of sodium concentration. (Note the break in the ordinate at 10 between positive and negative values). 
results for $\epsilon_{1}$ at $0.5 \mathrm{GHz}$ and $\mathrm{T}=238 \mathrm{~K}$ as a function of sodium concentration. With increasing sodium concentration, $\epsilon_{1}$ shows a strong enhancement, then decreases and reaches negative values around $4 \mathrm{MPNa}$, indicating the transition to metallic behaviour. A qualitatively similar behaviour has been reported by Mahaffey et al. /12/ and Breitschwerdt et al. $/ 13,14 /$, using different frequencies, however. The collection of experimental data available for $\epsilon_{1}$ of $\mathrm{Na}-\mathrm{NH}_{3}$ solutions is depicted in Figure 5. A steep rise of $\epsilon_{1}$ has been observed for $\mathrm{Li}-\mathrm{NH}_{3}$ solutions at concentrations < $2 \mathrm{MPLi}$ by Damay et al. /15/. They obtained $\epsilon_{1}$ from the analysis of ESR lineshapes at $9.3 \mathrm{GHz}$. There are indications, that the sharp rise of $\epsilon_{1}$ around $1 \mathrm{MPM}$ for frequencies near $10 \mathrm{GHz}$ in $\mathrm{Na}-\mathrm{NH}_{3} / 13,14 /$ and $\mathrm{Li}-\mathrm{NH}_{3}$ $/ 15 /$ solutions is due to a resonant like phenomenon.

Data on $\epsilon_{1}$ taken in the optical range (at $0.6 \mathrm{eV}$ ) are included in Figure 5, too. The behaviour of $\epsilon_{1}$ has the same trend, although the effect observed here is weaker and the fall to negative values of $\epsilon_{1}$ is slower. As might be expected from theory, the peak is rounded and shifted towards higher metal concentrations at these high frequencies $/ 16,17 /$. Similar results have been reported also for other $\mathrm{M}-\mathrm{NH}_{3}$ solutions $/ 2,17,18 /$. A similar rise of $\epsilon_{1}$ for a "hot" system approaching the MNMT has been observed by Nattland and Freyland in molten K$\mathrm{KCl}$ mixtures around $\mathrm{x}_{\mathrm{K}}=0.2 / 19 /$.

\section{References}

/1/ SCHINDEWOLF, U, Z. Phys. Chem. N. F. 1122 (1978) 153

/2/ THOMPSON, J C, "Electrons in Liquid Ammonia", Clarendon Press, Oxford, 1976

/3/ KÖHLER, W H and LAGOWSKI, J J, J. Phys. Chem. 73 (1969) 2329

/4/ SCHLAUF, M, Doctoral Thesis, University of Marburg, 1985

/5/ SCHLAUF, M and WINTER, R, Z. Phys. Chem. N. F. 156 (1988) 207

/6/ VERLEUR, H W, J. Opt. Soc. Am. 58 (1968) 1366

/7/ SCHÖNHERR, G, Z. Phys. Chem. N. F. 156 (1988) 231

/8/ HERZFELD, K F, Phys. Rev. 29 (1927) 701

/9/ MOTT, N F, "Metal-Insulator Transitions", Taylor \& Francis, London, 1990

/10/ KAVEH, M, Phil. Mag. B 52 (1985) L1

/11/ KRAMER, B, BERGMANN, G AND BRUYNSERAEDE, Y (eds.), "Localization,

Interaction, and Transport Phenomena", Springer-Verlag, Berlin, 1985

/12/ MAHAFFEY, D W, YERDE, D A, Rev. Mod. Phys. 40 (1968) 710

/13/ BREITSCHWERDT, K G AND RADSCHEIT, H, in "Electrons in Fluids" (eds. Jortner,

$\mathrm{J}$ and Kestner, N R), Springer-Verlag, Berlin, 1973

/14/ BREITSCHWERDT, K G AND RADSCHEIT, H, Ber. Bunsenges. Phys. Chem. 80 (1976) 797

/15/ DAMAY, P, LECLERCQ, F AND LELIEUR, J P, Phil. Mag. B 57 (1988) 75

/16/ GOETZE, W, in "Recent Developments in Condensed Matter Physics" (ed. Devreese, J)

Vol. 1, Plenum Press, New York, 1981

/17/ THOMPSON, J C, J. Solid State Chem. 54 (1984) 308

/18/ SOMOANO, R B and THOMPSON, J C, Phys. Rev. A 1 (1970) 376

/19/ NATTLAND, D and FREYLAND, W, Ber. Bunsenges. Phys. Chem. 93 (1989) 752 